\title{
Comparison of the protective effects of truncated bFGF and native bFGF against murine lung carcinoma
}

\author{
ZICHAO LUO $^{1,2^{*}}$, XINYUN PENG $^{3 *}$, HUASHAN SHI $^{1}$, CHANGYANG GONG $^{1}$, ZHIYONG QIAN $^{1}$ and LI YANG ${ }^{1}$ \\ ${ }^{1}$ State Key Laboratory of Biotherapy and Cancer Center, West China Hospital, West China Medical \\ School and ${ }^{2}$ School of Life Sciences, Sichuan University, Chengdu 610041, P.R. China; \\ ${ }^{3}$ Department of Zoology, University of Oklahoma, Norman, OK 73019, USA
}

Received December 3, 2010; Accepted January 29, 2011

DOI: $10.3892 / \mathrm{ijmm} .2011 .676$

\begin{abstract}
Basic fibroblast growth factor (bFGF), an angiogenic factor, exhibits pro-angiogenic abilities by interacting with tyrosine kinase receptors and heparin-sulfated proteoglycan receptors. Here, we designed an $\mathrm{N}$-, C-terminally truncated basic fibroblast growth factor (tbFGF) for immuno-therapy of murine lung carcinoma with PCEC hydrogel as adjuvant, comparing it with the wild-type bFGF. In vitro, tbFGF did not stimulate NIH-3T3 fibroblast proliferation. In vivo, after immunization, both tbFGF and bFGF were able to induce a robust bFGF-specific immune response. The protective antitumor investigation showed a significant inhibition of tumor growth and reduction of tumor vascularization detected by immunohistochemical staining and the alginate-encapsulated tumor cell assay in the tbFGF or the bFGF group. These data suggested that tbFGF can be used in the immunotherapy of tumors, without the risks associated with bFGF, which induces neovascularization in normal tissues.
\end{abstract}

\section{Introduction}

Basic fibroblast growth factor (bFGF/bFGF-2), demonstrated to be a multifunctional cytokine, belongs to the 23-member family of the fibroblast growth factors $(1,2)$. All the members of this family share a homologous core region that is composed of 120-130 amino acids, which are ordered into 12 antiparallel $\beta$-strands ( $\beta 1-\beta 12$ ) (3). Fibroblast growth factor (FGF), especially bFGF, plays a critical role in promoting proliferation, migration and differentiation of numerous cell types (4-6), and it also plays an important part in inducing angiogenesis

Correspondence to: Dr Li Yang, State Key Laboratory of Biotherapy and Cancer Center, West China Hospital, West China Medical School, Sichuan University, No. 1 Keyuan Road 4, Gaopeng Street, High Technological Zone, Chengdu, Sichuan 610041, P.R. China E-mail: yl.tracy73@gmail.com

${ }^{*}$ Contributed equally

Key words: truncated basic fibroblast growth factor, basic fibroblast growth factor, angiogenesis, anti-tumor and regulating cell apoptosis (7). Furthermore, bFGF, an angiogenic factor $(8,9)$, induces differentiation and invasion of several tumor cell lines that include prostate, bladder, renal, breast, pancreas and lung tumors as well as melanomas (4).

Angiogenesis, the physiological process of primary vascular plexus formation, has a critical role in tumor growth, progression and metastasis (10-12). Owing to its induction of angiogenesis (13) and overexpression in malignant tissue $(14,15)$, bFGF could be used as a target for tumor immunotherapy. However, bFGF is also widely distributed in normal tissues (16). The use of wild-type bFGF as an antigen for tumor immunotherapy may present the following problems: (i) the injected bFGF could be recognized as a self-component by the body's immune system, which can thus lead to a decrease in immunogenicity and even unresponsiveness (17) and (ii) the redundant, free bFGF in the body has the potential to promote tumor vessel growth. Therefore, we exploited an N-, C-terminally truncated version of the human bFGF as an antigen and compared it to normal bFGF. The tbFGF retained the original bFGF receptor binding domains, which are the FGF receptor (FGFR) binding domains and also part of the heparin-binding domain; hence tbFGF may have the immunogenicity but not the angiogenic activity (18).

Adjuvants are the substances that improve the immune response against co-inoculated antigens, while not having any specific antigenic effect (19-21). Hydrogel has been explored as a drug-delivery system and its role as an adjuvant acting in vaccine has been widely studied (22-24). Recently, we prepared a new kind of biodegradable and thermosensitive hydrogel (poly( $\varepsilon$-caprolactone)-poly(ethylene glycol)-poly( $\varepsilon$ caprolactone), PCEC), which showed to be an injectable local drug delivery system, without signs of toxicity (25).

In this study, we investigated a new kind of cancer vaccine: the tbFGF loaded in PCEC hydrogel as an adjuvant, which was suggested to inhibit tumor angiogenesis and to elicit the anti-tumor effect by means of antibody treatment. Our data indicate that tbFGF, as a substitute for normal bFGF, can be used in tumor immunotherapy.

\section{Materials and methods}

Preparation of bFGF, truncated bFGF peptide and loading on PCEC hydrogel. Both the human bFGF and the tbFGF 


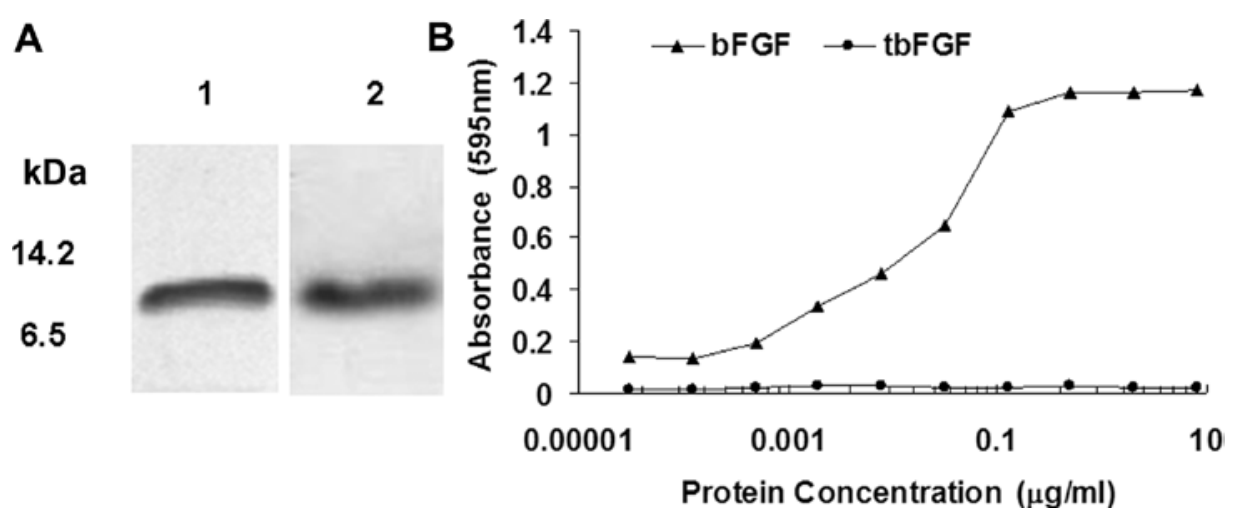

Figure 1. Identification of the truncated bFGF (tbFGF) peptide and its proliferative bioactivity. (A) Recombinant tbFGF was identified by Coomassie Blue staining (panel 1) and Western blot analysis (panel 2) with anti-bFGF antibody. (B) The bioactivity of tbFGF and bFGF was measured in NIH-3T3 cells by a proliferation assay. Compared to the $\mathrm{ED}_{50}$ of normal bFGF (approximately $50 \mathrm{ng} / \mathrm{ml}$ ), the $\mathrm{ED}_{50}$ of tbFGF was not detected.

peptide can validly bind FGFRs on the cell surface because of their structures including the bFGF receptor binding site and part of the heparin-binding site. The two recombinant peptides were synthesized according to previous reports $(26,27)$. Briefly, the bFGF and tbFGF cDNA sequence were inserted in the prokaryotic expression plasmid pQE30 (Qiagen Inc., Valencia, CA, USA) to get 6xHis and tbFGF fusion protein. The two recombinant proteins were expressed in TG-1 as an inclusion body. The pellet was lysed by high pressure (APV 2000, Denmark) after a series of pre-treatments. The supernatant were successively applied to SP-ion-exchange chromatography and Ni-chelating sepharose affinity chromatography. The purity of bFGF and tbFGF can be reached $99 \%$. At the same time, the proteins were loaded on thermosensitive hydrogels prepared as previously described (28).

Cell culture. Lewis lung carcinoma LL/2 cells and NIH-3T3 cells were purchased from the American Type Culture Collection (ATCC; Rockville, MD, USA). These cells grew in DMEM supplement with $10 \% \mathrm{FBS}, 100 \mathrm{IU} / \mathrm{ml}$ penicillin and $100 \mu \mathrm{g} / \mathrm{ml}$ streptomycin. All cells were cultured in an atmosphere of $5 \% \mathrm{CO}_{2}$ at $37^{\circ} \mathrm{C}$.

Animals and immunization. Female C57BL/6J mice were purchased from the Laboratory Animal Centre of Sichuan University (Chengdu, China). Mice (6-weeks old) were immunized by hypodermic injection with bFGF/tbFGF (20 $\mu \mathrm{g} / \mathrm{dose})$ with hydrogel, or normal saline (NS) on 0,2 and 4 weeks. The serum samples were collected on $0,1,2,3,4,5$ and 6 weeks.

ELISA determination of anti-bFGF antibody. ELISA was used to measure bFGF-specific antibody responses. Briefly, 96-well microtiter plates (Falcon) were coated overnight at $4^{\circ} \mathrm{C}$ with $0.5 \mu \mathrm{g} /$ well of bFGF in sodium carbonate buffer, $\mathrm{pH}$ 9.6. After the plates were washed by PBST (1\% Tween in PBS) and blocked with 5\% skim milk dissolved in PBST, serial dilutions of serum from mice were added to the wells and incubated for $2 \mathrm{~h}$ at $37^{\circ} \mathrm{C}$. Bound antibodies were detected with HRP-conjugated goat anti-mouse IgG antibodies diluted 1:5000, and visualized using a substrate-chromogen solution. Enzyme activity was measured at an absorbance of $450 \mathrm{~nm}$ in a Bio-Rad microtiter plate reader.
CD31. A monoclonal rabbit anti-mouse immunoglobulin was used in the specific staining for endothelial cells. Briefly, tumor samples were fixed in acetone, incubated and stained with an antibody reactive to $\mathrm{CD} 31$ as previously described (17).

Alginate-encapsulated tumor cell assay. To explore the effect of bFGF or tbFGF on anti-angiogenesis in vivo, the alginateencapsulated tumor cell assay were performed as previously described $(29,30)$. LL/2 cells were resuspended in a $1.5 \%$ solution of sodium alginate and added dropwise into a swirling solution of $250 \mathrm{mM}$ calcium chloride at $37^{\circ} \mathrm{C}$. Alginate beads containing $\sim 1 \times 10^{5}$ tumor cells per bead were implanted subcutaneously (s.c.) into an incision made in the dorsal side of the immunized female C57BL/6J mice. Twelve days after the implantation, mice were injected intravenously (i.v.) with $100 \mu \mathrm{l}$ of a $100 \mathrm{mg} / \mathrm{kg}$ FITC-dextran solution (Sigma). The beads were exposed surgically and photographed at $20 \mathrm{~min}$. The uptake of FITC-dextran was quantified against a standard curve of FITC-dextran.

\section{Results}

The proliferative bioactivity of $t b F G F$. Recombination of tbFGF was verified by Coomassie Blue staining (Fig. 1A panel 1) and Western blotting (Fig. 1A, panel 2) with an antibFGF antibody. The molecular weight of tbFGF was $10.9 \mathrm{kDa}$, which was in accordance with the theoretical value. Compared to bFGF, tbFGF did not show any proliferative bioactivity in NIH-3T3 cells in vitro, even with the tbFGF concentration of $10 \mu \mathrm{g} / \mathrm{ml}$ in the culture medium (Fig. 1B).

Anti-bFGF immune response of tbFGF. C57BL/6J mice were given subcutaneous injection near axillas for three times at 2-week intervals (0, 2 and 4 weeks) per mouse per injection, with $20 \mu \mathrm{g}$ of bFGF or tbFGF with $25 \mathrm{wt} \%$ PCEC copolymer (28). Sera were collected from each immunized mouse at 0,1 , 2, 3, 4, 5 and 6 weeks after immunization, and bFGF-specific total serum IgG antibody titers were assayed by ELISA (Fig. 2A). The expression level of bFGF-specific antibody in the hydrogel/bFGF group or the hydrogel/tbFGF group exhibited a significant and sustained increase after the first immunization. 

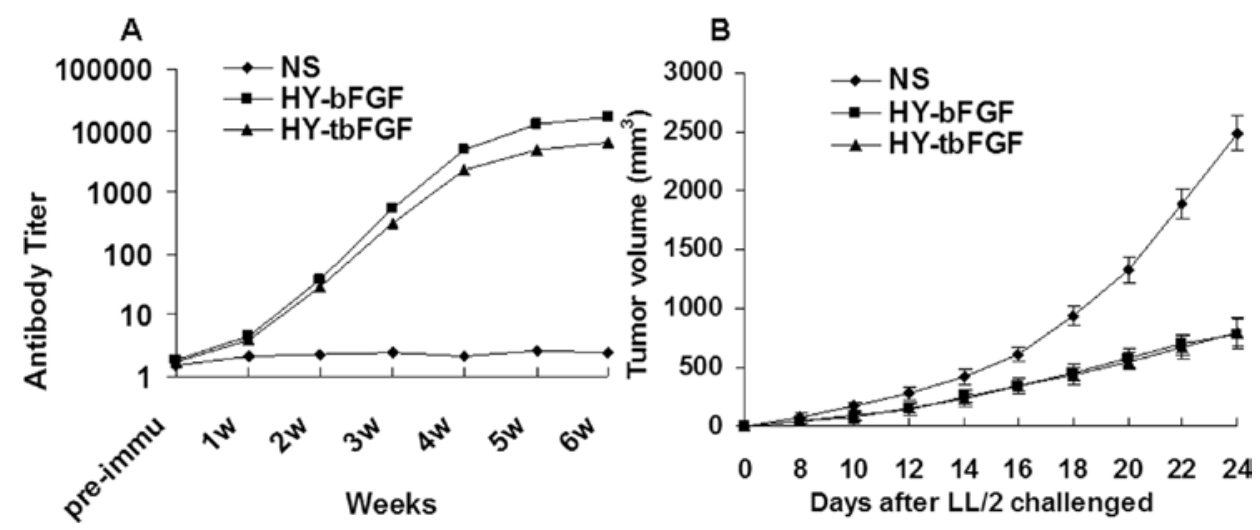

Figure 2. Induction of the expression of the bFGF-specific antibody and protective anti-tumor immunity. Mice (5/group) were immunized with $20 \mu \mathrm{g} b F G F$

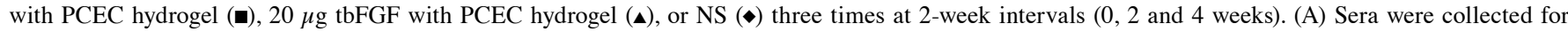
6 weeks, and the bFGF-specific antibody was determined by ELISA using the normal bFGF-coated plates. (B) After the last immunization, mice were challenged s.c. with $5 \times 10^{5} \mathrm{LL} / 2$ cells. There was a great difference in tumor volume between the experimental groups (HY-bFGF, HY-tbFGF) and the control group (NS).

A
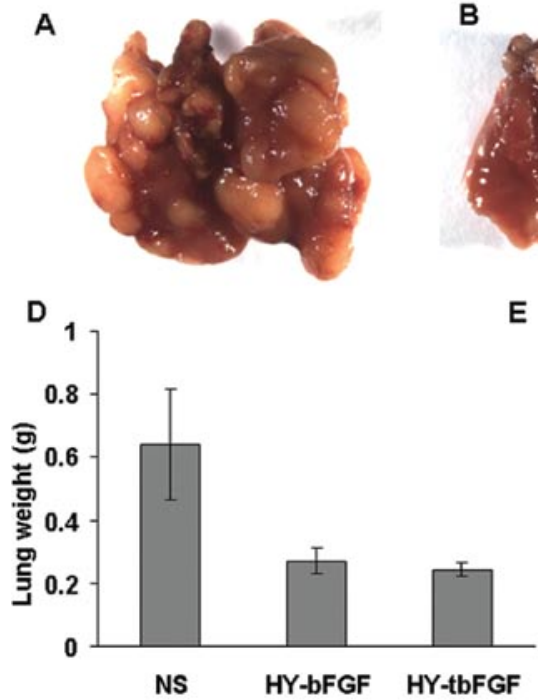

E
B
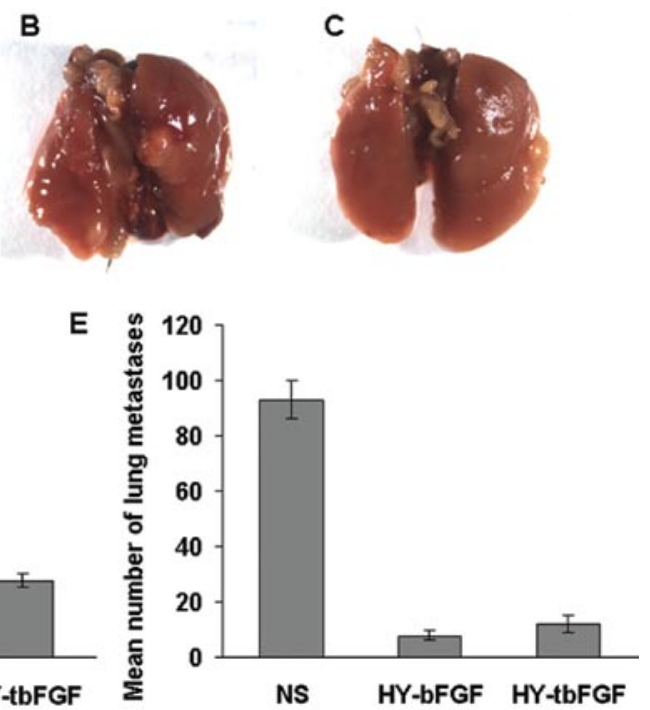

Figure 3. Induction of the therapeutic anti-tumor immunity. C57BL/6J mice were immunized with HY-bFGF, HY-tbFGF or NS as described. The mouse lung metastasis model was established by i.v. injection of $2 \times 10^{5} \mathrm{LL} / 2$ cells. Mice were sacrificed 28 days after tumor cell inoculation and lung weights and the number of lung metastases were assessed. Representative lungs from (A) normal saline (NS), (B) HY-bFGF and (C) HY-tbFGF. (D) Lung weight and (E) number of lung metastases. The lungs from HY-bFGF and HY-tbFGF-treated mice showed significant difference compared to the NS group. There was no distinct difference between the HY-bFGF and the HY-tbFGF groups.

The anti-bFGF titers in animals receiving hydrogel/bFGF and hydrogel/tbFGF were not significantly different, but much higher than those in the normal saline (NS) group.

Antitumor immunity effects of bFGF and tbFGF in vivo. To investigate the protective anti-tumor immunity, the C57BL/6J mice were immunized by s.c. injection of hydrogel/bFGF, hydrogel/tbFGF or normal saline (NS) alone at 2 -week intervals for three times. After the last immunization, the mice of all groups were challenged with $5 \times 10^{5} \mathrm{LL} / 2$ cancer cells by s.c. injection or $2 \times 10^{5} \mathrm{LL} / 2$ cancer cells by i.v. injection. There was a significant anti-tumor effect in the hydrogel/bFGF and hydrogel/tbFGF groups, but not in the NS group (Fig. 2B). There was no significant difference between the hydrogel/ $\mathrm{bFGF}$ and the hydrogel/tbFGF groups.

In the LL/2 Lewis lung metastasis model, the immunity with hydrogel/bFGF or hydrogel/tbFGF showed a remarkable suppression on the formation, growth and development of lung metastasis. The lung weight and numbers of lung metastasis in the hydrogel/bFGF or hydrogel/tbFGF groups were obviously lower than those in the NS group. However, there were no significant differences between the hydrogel/bFGF and the hydrogel/tbFGF groups (Fig. 3).

Inhibition of angiogenesis. Angiogenesis of tumor sections was compared between hydrogel/bFGF, hydrogel/tbFGF and the NS group. The hydrogel/bFGF or hydrogel/tbFGF group resulted in apparent inhibition of angiogenesis compared to the control group (Fig. 4A-C). The number of microvessels also showed a distinct decrease in immunohistochemical staining of sections stained with an antibody reactive to CD31 (Fig. 4D).

To further investigate the effect of angiogenesis inhibition, the alginate-encapsulation tumor cell assay was used to 

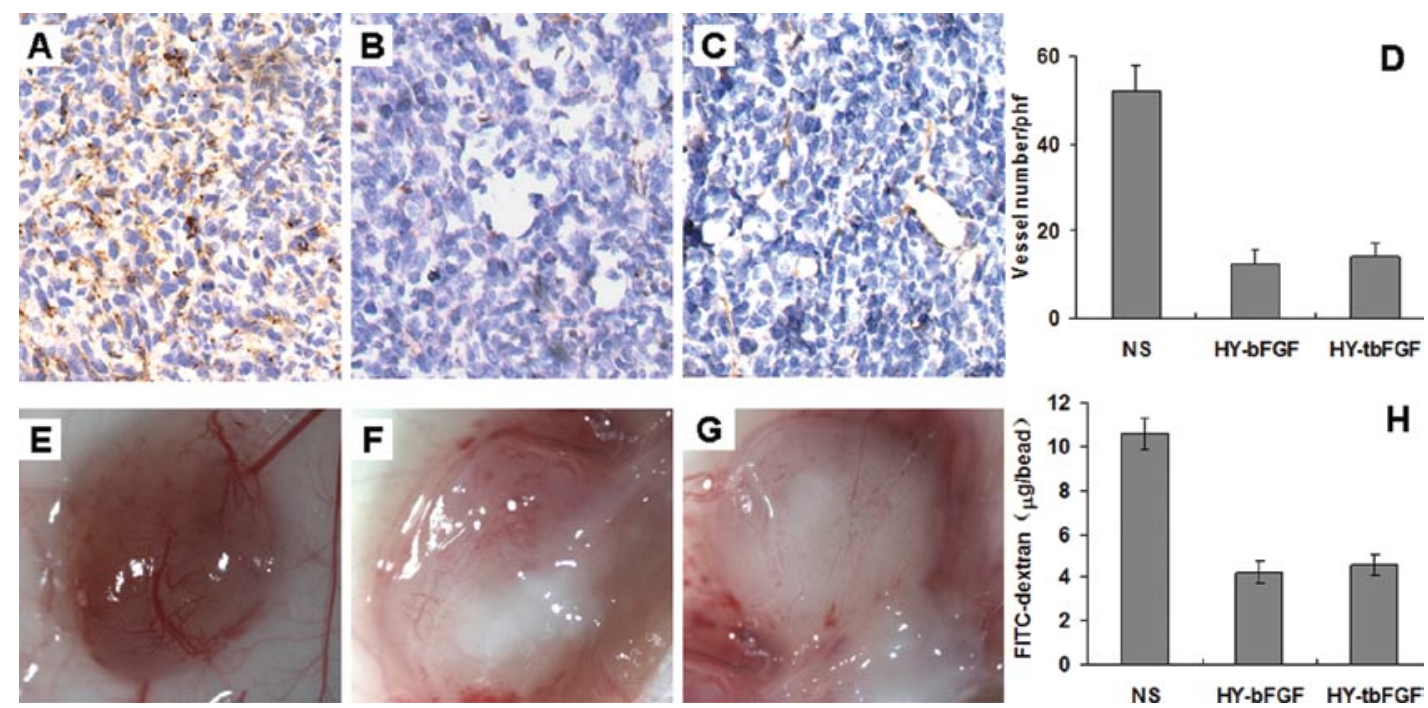

Figure 4. Inhibition of tumor angiogenesis in vivo. The immunized C57BL/6J mice were sacrificed 28 days after injection with LL/2 cells. Sections of frozen LL/2 tumor tissues obtained from mice immunized with (A) NS, (B) HY-bFGF or (C) HY-tbFGF, respectively. Vessel density was determined by counting the number of the microvessels per high-power field (D) in tumor tissue stained with antibodies to CD31. Vascularization of alginate implants. Mice were immunized as above. Alginate beads containing $1 \times 10^{5} \mathrm{LL} / 2$ cells per bead were implanted s.c. into the backs of mice on day 7 after the last immunization. After 12 days, beads were surgically removed (E-G), and FITC-dextran was quantified (H). The beads were from the mice treated with (E) NS, (F)HY-bFGF, or (G) HY-tbFGF groups, respectively. Compared to the NS group, both vessel density and FITC-dextran uptake showed a significant decrease in both the HY-bFGF and HY-tbFGF immunized groups.

quantify the angiogenesis in alginate implants by assaying the uptake of FITC-dextran into the beads. Compared with the NS group, vascularization of alginate beads was apparently reduced in the hydrogel/bFGF or hydrogel/tbFGF immunized mice (Fig. 4E-H). Nevertheless, no distinct difference was observed between the hydrogel/bFGF and hydrogel/tbFGF groups. These data suggest that tumor angiogenesis was inhibited in the hydrogel/bFGF or hydrogel/tbFGF immunized mice, which led to suppression of tumor growth.

\section{Discussion}

Angiogenesis, formation of new blood vessels, is the key factor in both physiological and pathological processes involving neovascularization, such as, embryogenesis (31-33), wound healing (34), and tumor growth (4-6). bFGF, a potent angiogenic mitogen, plays a critical role in cancer development (35). Endogenous bFGF expression can seriously influence the initial period of tumor growth and angiogenesis in human endometrial adenocarcinoma as determined in a system which could express conditional bFGF (36). Furthermore, it has been proven that exogenous bFGF could induce a host-inflammatory response related to bFGF-induced tumor growth and metastasis, which may be dependent on endogenous VEGF-A (37).

Hori et al have shown that an anti-bFGF monoclonal antibody, 3H3, a specific inhibitor of bFGF, exhibited a powerful immuno-neutralizing activity and inhibited angiogenesis and solid tumor growth (38). Owing to the overexpression and release from tumor cells themselves or from stromal cells, bFGF may promote proliferation of tumor cells. This may be the reason that bFGF exerts an oncogenic effect as has been demonstrated in mouse models (39). Therefore, immunotherapy based on the bFGF may be an effective way for the tumor treatment, without ignoring the fact that abundance of

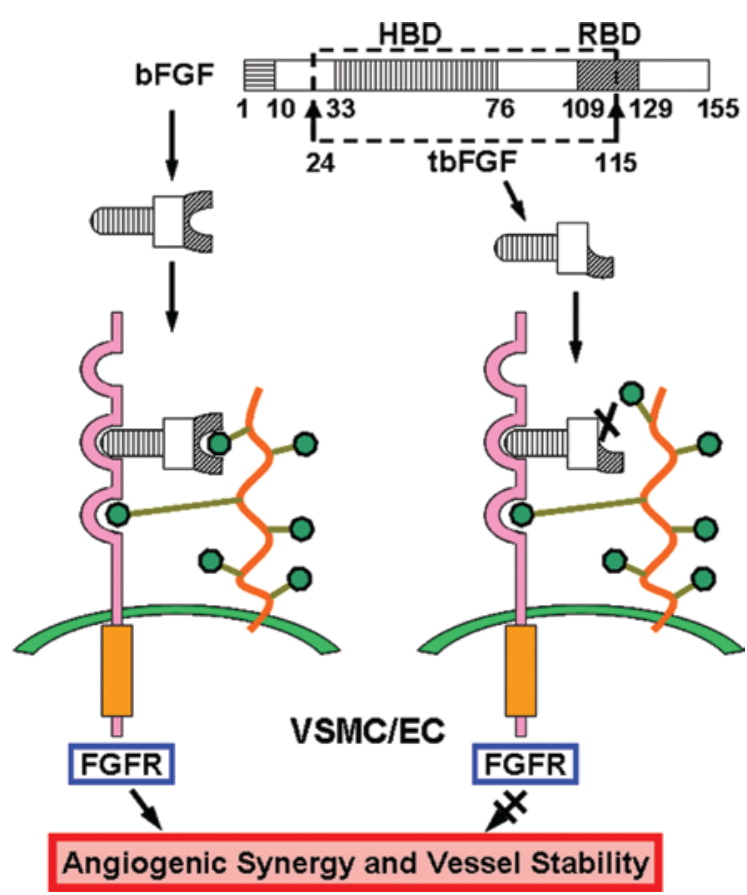

Figure 5. Simplified model illustrating the different effects of bFGF and tbFGF on angiogenesis. Both bFGF and tbFGF are recognized by FGF receptor (FGFR), but only the bFGF can activate the signaling pathway of FGFR by phosphorylation, which plays an important role in regulating angiogenesis. Lacking a partial structure of bFGF, tbFGF binds to the FGFR as well. However, it does not take part in angiogenesis.

bFGF may promote tumor growth through induction of new vessel formation.

Furthermore, administration of exogenous bFGF can induce many kinds of responses in vivo. bFGF has been shown to induce rapid neovascularization in the kindey capsule, cornea, or the skin $(9,40,41)$. This is a major problem when 
using normal bFGF for immunotherapy. In our study, tbFGF did not show any proliferation of NIH-3T3 cells in vitro, but a completely opposite result was observed with bFGF (Fig. 1B). Both hydrogel/bFGF and hydrogel/tbFGF induced the expression of bFGF-specific antibodies (Fig. 2), which suggests that tbFGF could be a substitute for bFGF in immunotherapy.

The anti-tumor effect of immunotherapy with bFGF or tbFGF was very similar. In those two groups, tumor growths were depressed. Analyzing tumor microvessels with CD31 immunohistochemistry analysis and the alginate-encapsulated assay showed an obvious reduction of microvessel density in the bFGF and tbFGF groups, compared to the NS group (Fig. 4).

The mechanism of tbFGF used as an antigen applied to tumor immunotherapy may be interpreted as follows (Fig. 5): (i) the same structure of bFGF and tbFGF may be responsible for the immunogenicity of tbFGF; (ii) although the FGFR can recognize and bind to tbFGF, the signaling pathway which induces angiogenesis is inhibited owing to the deficiency in the structure compared to the normal bFGF.

In conclusion, the present study has shown that the PCEC hydrogel may be used as an effective carrier for immunotherapy of tbFGF. Moreover, owing to the strong immunogenicity and effective anti-tumor effect of tbFGF, tbFGF may find wide use in tumor immunotherapy.

\section{Acknowledegments}

The study was supported by the Program for New Century Excellent Talents in University (NCET)(NCET-10-0575) and the National Natural Science Foundation of China (Grant No. 30973453).

\section{References}

1. Javerzat S, Auguste P and Bikfalvi A: The role of fibroblast growth factors in vascular development. Trends Mol Med 8: 483-489, 2002.

2. Delrieu I: The high molecular weight isoforms of basic fibroblast growth factor (FGF-2): an insight into an intracrine mechanism. FEBS Lett 468: 6-10, 2000 .

3. Johnson DE, Lee PL, Lu J and Williams LT: Diverse forms of a receptor for acidic and basic fibroblast growth factors. Mol Cell Biol 10: 4728-4736, 1990

4. Basilico C and Moscatelli D: The FGF family of growth factors and oncogenes. Adv Cancer Res 59: 115-165, 1992.

5. Werner S: Keratinocyte growth factor: a unique player in epithelial repair processes. Cytokine Growth Factor Rev 9: 153-165, 1998.

6. Bikfalvi A, Klein S, Pintccci G and Rifkin DB: Biological roles of fibroblast growth factor-2. Endocr Rev 18: 26-45, 1997.

7. Coleman AB: Positive and negative regulation of cellular sensitivity to anti-cancer drugs by FGF-2. Drug Resist Updat 6 : 85-94, 2003

8. Montesano R, Vassalli JD, Baird A, Guillemin R and Orci L: Basic fibroblast growth factor induces angiogenesis in vitro. Proc Natl Acad Sci USA 83: 7297-7301, 1986.

9. Folkman J and Klagsbrun M: Angiogenic factors. Science 235: 442-447, 1987.

10. Risau W: Mechanisms of angiogenesis. Nature 386: 671-674, 1997.

11. Folkman $\mathrm{J}$ : What is the evidence that tumors are angiogenesis dependent? J Natl Cancer Inst 82: 4-6, 1990.

12. Makrilia N, Lappa T, Xyla V, Nikolaidis I and Syrigos K: The role of angiogenesis in solid tumours: an overview. Eur J Intern Med 20: 663-671, 2009

13. Thomas KA: Fibroblast growth factors. FASEB J 1: 434-440, 1987.
14. Gomm JJ, Smith J, Ryall GK, Baillie R, Turnbull L and Coombes RC: Localization of basic fibroblast growth factor and transforming growth factor beta 1 in the human mammary gland. Cancer Res 51: 4685-4692, 1991.

15. Ke Y, Fernig DG, Wilkinson MC, et al: The expression of basic fibroblast growth factor and its receptor in cell lines derived from normal human mammary gland and a benign mammary lesion. J Cell Sci 106: 135-143, 1993.

16. Rifkin DB and Moscatelli D: Recent developments in the cell biology of basic fibroblast growth factor. J Cell Biol 109: 1-6, 1989.

17. Zhang XP, Yang L, Shi HS, et al: An N-, C-terminally truncated basic fibroblast growth factor and LPD (liposome-polycation-DNA) complexes elicits a protective immune response against murine colon carcinoma. Cancer Biol Ther 10: 1-6, 2010.

18. Plum SM, Holaday JW, Ruiz A, Madsen JW, Fogler WE and Fortier AH: Administration of a liposomal FGF-2 peptide vaccine leads to abrogation of FGF-2-mediated angiogenesis and tumor development. Vaccine 19: 1294-1303, 2000.

19. Proceedings of a conference. Bergen, Norway, June 18-21, 1996. Modulation of the immune response to vaccine antigens. Dev Biol Stand 92: 1-372, 1998.

20. Wilson-Welder JH, Torres MP, Kipper MJ, Mallapragada SK, Wannemuehler MJ and Narasimhan B: Vaccine adjuvants: current challenges and future approaches. J Pharm Sci 98: 1278-1316, 2009.

21. O'Hagan DT and Valiante NM: Recent advances in the discovery and delivery of vaccine adjuvants. Nat Rev Drug Discov 2: 727-735, 2003.

22. Jeong B, Bae YH, Lee DS and Kim SW: Biodegradable block copolymers as injectable drug-delivery systems. Nature 388 : 860-862, 1997.

23. Miyata T, Asami N and Uragami T: A reversibly antigenresponsive hydrogel. Nature 399: 766-769, 1999.

24. Casadei MA, Pitarresi G, Calabrese R, Paolicelli P and Giammona G: Biodegradable and $\mathrm{pH}$-sensitive hydrogels for potential colon-specific drug delivery: characterization and in vitro release studies. Biomacromolecules 9: 43-49, 2008.

25. Gong C, Shi S, Wu L, et al: Biodegradable in situ gel-forming controlled drug delivery system based on thermosensitive PCL-PEG-PCL hydrogel. Part 2: sol-gel-sol transition and drug delivery behavior. Acta Biomater 5: 3358-3370, 2009.

26. Gou ML, Huang MJ, Qian ZY, et al: Preparation of anionic poly(epsilon-caprolactone)-poly(ethylene glycol)-poly(epsiloncaprolactone) copolymeric nanoparticles as basic protein antigen carrier. Growth Factors 25: 202-208, 2007.

27. Chen X, Wang X, Wang Y, et al: Improved tumor-targeting drug delivery and therapeutic efficacy by cationic liposome modified with truncated bFGF peptide. J Control Release 145: 17-25, 2010.

28. Gong CY, Shi S, Peng XY, et al: Biodegradable thermosensitive injectable PEG-PCL-PEG hydrogel for bFGF antigen delivery to improve humoral immunity. Growth Factors 27: 377-383, 2009.

29. Hoffmann J, Schirner M, Menrad A and Schneider MR: A highly sensitive model for quantification of in vivo tumor angiogenesis induced by alginate-encapsulated tumor cells. Cancer Res 57: 3847-3851, 1997

30. Liu JY, Wei YQ, Yang L, et al: Immunotherapy of tumors with vaccine based on quail homologous vascular endothelial growth factor receptor-2. Blood 102: 1815-1823, 2003.

31. Coleman AB, Metz MZ, Donohue CA, Schwarz RE and Kane SE: Chemosensitization by fibroblast growth factor- 2 is not dependent upon proliferation, S-phase accumulation, or p53 status. Biochem Pharmacol 64: 1111-1123, 2002.

32. Macias D, Ganan Y, Ros MA and Hurle JM: In vivo inhibition of programmed cell death by local administration of FGF-2 and FGF-4 in the interdigital areas of the embryonic chick leg bud. Anat Embryol (Berl) 193: 533-541, 1996.

33. Yokoyama Y, Ozawa S, Seyama Y, et al: Enhancement of apoptosis in developing chick neural retina cells by basic fibroblast growth factor. J Neurochem 68: 2212-2215, 1997.

34. Schwartz SM and Liaw L: Growth control and morphogenesis in the development and pathology of arteries. J Cardiovasc Pharmacol 21 (Suppl. 1): S31-S49, 1993.

35. Dow JK and deVere White RW: Fibroblast growth factor 2: its structure and property, paracrine function, tumor angiogenesis, and prostate-related mitogenic and oncogenic functions. Urology 55: 800-806, 2000. 
36. Giavazzi R, Giuliani R, Coltrini D, et al: Modulation of tumor angiogenesis by conditional expression of fibroblast growth factor-2 affects early but not established tumors. Cancer Res 61: 309-317, 2001.

37. Tsunoda S, Nakamura T, Sakurai H and Saiki I: Fibroblast growth factor-2-induced host stroma reaction during initial tumor growth promotes progression of mouse melanoma via vascular endothelial growth factor A-dependent neovascularization. Cancer Sci 98: 541-548, 2007.

38. Hori A, Sasada R, Matsutani E, et al: Suppression of solid tumor growth by immunoneutralizing monoclonal antibody against human basic fibroblast growth factor. Cancer Res 51: 6180-6184, 1991.
39. Ribatti D, Vacca A, Rusnati M and Presta M: The discovery of basic fibroblast growth factor/fibroblast growth factor-2 and its role in haematological malignancies. Cytokine Growth Factor Rev 18: 327-334, 2007.

40. Davidson JM, Klagsbrun M, Hill KE, et al: Accelerated wound repair, cell proliferation, and collagen accumulation are produced by a cartilage-derived growth factor. J Cell Biol 100: 1219-1227, 1985

41. Hayek A, Culler FL, Beattie GM, Lopez AD, Cuevas P and Baird A, et al: An in vivo model for study of the angiogenic effects of basic fibroblast growth factor. Biochem Biophys Res Commun 147: 876-880, 1987. 